\title{
Angina in patients with occluded aorto-coronary vein grafts
}

\author{
V. Di Luzio, P. R. Roy, and E. Sowton \\ From the Cardiac Department, Guy's Hospital, London
}

Five patients with occluded vein grafts were found after operation to be free from angina. These patients had electrocardiographic evidence of asymptomatic myocardial infarction occurring early in the postoperative period.

Fifteen patients with occluded vein grafts were compared before and after operation in terms of symptoms, coronary arterial and graft anatomy, exercise tolerance, atrial pacing, and findings on cardiac catheterization and angiography.

Often angina was absent in the early postoperative period, but recurred after leaving hospital. Occlusion of the left graft is much more likely to be associated with recurrence of symptoms, exercise limitation, and worsening of left ventricular function than is occlusion of the right graft.

It is widely accepted that coronary bypass surgery is an effective means of improving disabled patients who suffer from severe intractable angina pectoris.

High percentages of patients have been reported to be improved in that they returned to normal activity and were free from angina after operation; in others, the frequency and severity of anginal attacks were reduced (Spencer et al., 1971; Parsonnet et al., 1973; Green et al., 1970), so that approximately 80 per cent of patients can be regarded as greatly improved with regard to pain.

Previous reports have also suggested that freedom from angina after operation correlates positively with vein graft patency (Ross et al., I972). Though graft occlusions have been demonstrated after operation in patients in whom there was no improvement, or even deterioration of the clinical state (Spencer et al., I97I ; Parsonnet et al., 1973; Ross et al., 1972), complete data concerning the state of angina following graft closure are not yet available. In addition the potentially harmful consequences of unsuccessful surgery on cardiac function have not yet been sufficiently studied.

The purpose of this communication is to report the pattern of angina in a group of 15 patients who, at a postoperative study, were found to have occluded vein grafts. The coronary arterial and graft anatomy and cardiac function assessed by exercise tolerance, atrial pacing, cardiac catheterization, and angiography were compared before and after operation. Received I August 1973.

\section{Subjects and methods}

Fifteen patients, 12 men and 3 women, aged 36 to 71 (mean 52) at the postoperative study, were found to have one or both the venous grafts occluded. Ten patients had been previously included in a programmed routine postoperative study with their informed consent. Five other patients were subsequently restudied several months after operation because of recurrent angina.

All patients had severe preoperative angina which was resistant to medical therapy. Twelve patients were taking practolol before operation. Drug therapy was discontinued during the early postoperative period and was restarted only if angina recurred. Documented previous myocardial infarction occurred once in 3 patients, twice in I patient, and three times in I patient. Three patients had emergency operations: 2 for pain of increasing frequency and severity at rest, unresponsive to medical treatment, and I for recurrent episodes of ventricular tachycardia associated with sudden clinical deterioration and cardiogenic shock.

The initial coronary arteriograms in all patients showed severe stenosis $(>80 \%)$ or a total occlusion of one or more major coronary arteries. The left anterior descending coronary artery was involved in 12 patients, the circumflex artery in 4 patients, and the right coronary artery in 15 patients. Thirteen patients had two grafts, and 2 patients had only one graft inserted. When two grafts were inserted, one was to the right coronary artery and one to a major branch of the left.

Repeat coronary arteriography and venous graft angiography were performed between 2 and ro months after operation (mean 5 months). Of the 28 grafts, 8 could not be selectively entered. In these patients an aortogram was performed which showed the stump of 
the occluded grafts in 3 patients. In the remainder ( 5 grafts in 4 patients) no evidence of graft patency was obtained. Subsequently, 2 of the latter 4 patients underwent a second bypass operation and their grafts were found to be occluded. Thus, 25 of the 28 grafts were positively shown to be occluded and the remaining 3 (in 2 patients) were extremely likely to be blocked.

Patients were classified into 3 groups.

Group $A$ consisted of patients with both grafts occluded (5 patients).

Group BI consisted of patients with the left graft occluded and right graft patent (6 patients).

Group $B 2$ consisted of patients with the left graft patent and right graft occluded (4 patients).

The patient with a single occluded graft to the right coronary artery was classified in group B2. The patient with a single occluded graft to the left anterior descending coronary artery was classified in group $\mathrm{Br}$.

Historical assessment of symptoms and clinical examination was performed before operation and serially after operation. Serial electrocardiograms, chest $x$-rays, and routine laboratory tests were performed before and after operation. Angina was graded from $I-4: I$ indicated angina on severe exertion; 2 , angina on moderate exertion; 3, angina on slight exertion; 4, angina on slight exertion and at rest (Ross et al., 1972). The preoperative grade of angina was compared with that of 3 postoperative periods, namely the early postoperative, the time of restudy, and the late follow-up period. The early postoperative period was considered to be within the 2 weeks after operation, during which patients were freely mobilized. The late follow-up period was considered to start one month from the time of restudy.

\section{Atrial pacing test}

An atrial pacing test was performed at the time of the first coronary arteriogram and at the postoperative study. In both instances beta-blocking drugs were discontinued 3 days before the investigation. Baseline recordings of the aortic, left ventricular systolic, and diastolic pressures were made, together with a standard electrocardiogram lead; the mid-thorax was taken as the zero reference point.

Atrial pacing was started at a pacing rate of approximately Io beats a minute faster than the resting heart rate. The pacing rate was increased at minute intervals by ro beats a minute to a maximum of 160 beats a minute, or until typical chest pain or atrioventricular conduction disturbances occurred. The pacing rate at which angina occurred was recorded as the 'pain threshold', and the typical ischaemic changes in the electrocardiogram at this rate were noted. Left ventricular systolic and diastolic pressures were measured at the end of each pacing interval and at the onset of angina if it occurred. The left ventricular end-diastolic pressure was recorded after the ' $a$ ' wave and an average reading was taken from 5 consecutive beats.

Patients with preinfarction angina and those with high resting left ventricular end-diastolic pressures ( 25 to 30 $\mathrm{mmHg}$ ) were excluded from the atrial pacing test. Patients showing evidence of atrioventricular conduction disturbance beyond the usual prolongation of PR interval during atrial pacing were also excluded from these results.

\section{Exercise test}

Pre- and postoperative exercise tests were performed in the upright position on an Elema Schonander bicycle ergometer. An initial warm-up period of 3 minutes at 200 kilopond-metres $/ \mathrm{min}(\mathrm{kpm} / \mathrm{min})$ was followed by rest until the heart rate had returned to the initial values. The exercise test was then started at an initial work load of $200 \mathrm{kpm} / \mathrm{min}$ for 3 minutes. The work load was subsequently increased by $200 \mathrm{kpm} / \mathrm{min}$ until the patient stopped because of angina, dyspnoea, or tiredness. Lead $\mathrm{V}_{5}$ of the electrocardiogram was recorded at oneminute intervals and at the end of each work load. The total work and the presence or absence of $T$ wave or ST segment abnormalities in the electrocardiogram was recorded at the cessation of exercise.

\section{Results}

The pre- and postoperative grades of angina in the patients of this series, who at restudy were found to have one or both the venous grafts occluded, are illustrated in Fig. I. Before operation 4 patients had grade 4 angina, ro had grade 3 , and I patient had grade 2. During the early postoperative period while the patients were being freely mobilized, angina was absent in 13 patients, and residual grade I angina was noted in 2 patients. During the subsequent period up to the time of restudy, angina recurred in Io patients so that 5 patients had angina of the same grade as before operation and 5 had angina of a less severe grade (the residual grade I angina present in 2 patients early after operation gradually increased in severity). During the early follow-up period 2 of the ro patients suffering from angina had an acute myocardial infarction from which they recovered; angina recurred in both patients.

Five patients in the whole group remained free from angina. In 3 of the 5 angina-free patients characteristic electrocardiographic changes of a stabilized myocardial infarction were observed (Fig. 2) during the early follow-up period. In the fourth patient the electrocardiogram showed persisting signs of anterior subendocardial damage and a change in the direction of the mean frontal plane QRS vector (Fig. 3). In the fifth patient deep $Q$ waves in leads II, III, and aVF, and a Qs pattern in leads VI to V5 were present before operation. No further electrocardiographic changes were observed after operation. None of these patients complained of chest pain after operation or of any other symptoms referable to the cardiovascular system. 


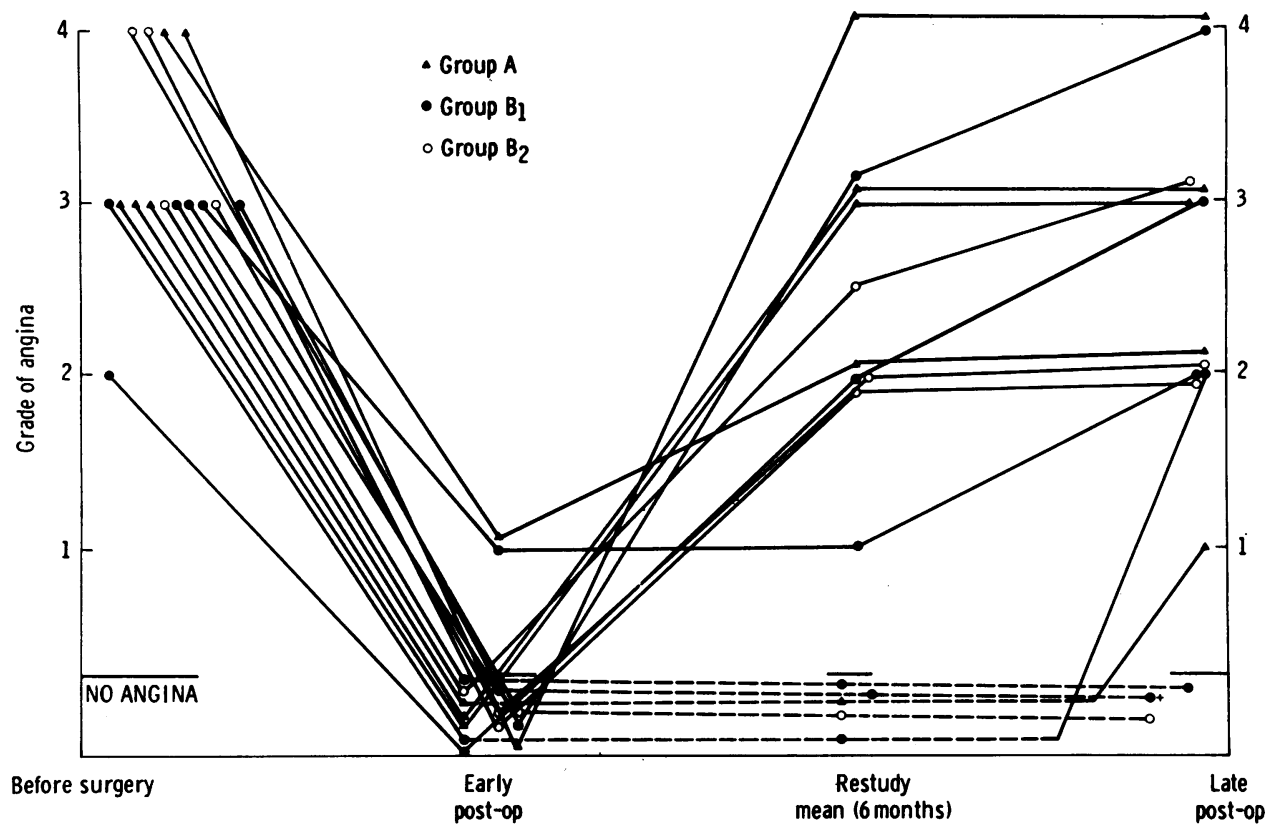

FIG. I Grade of angina before and after operation.

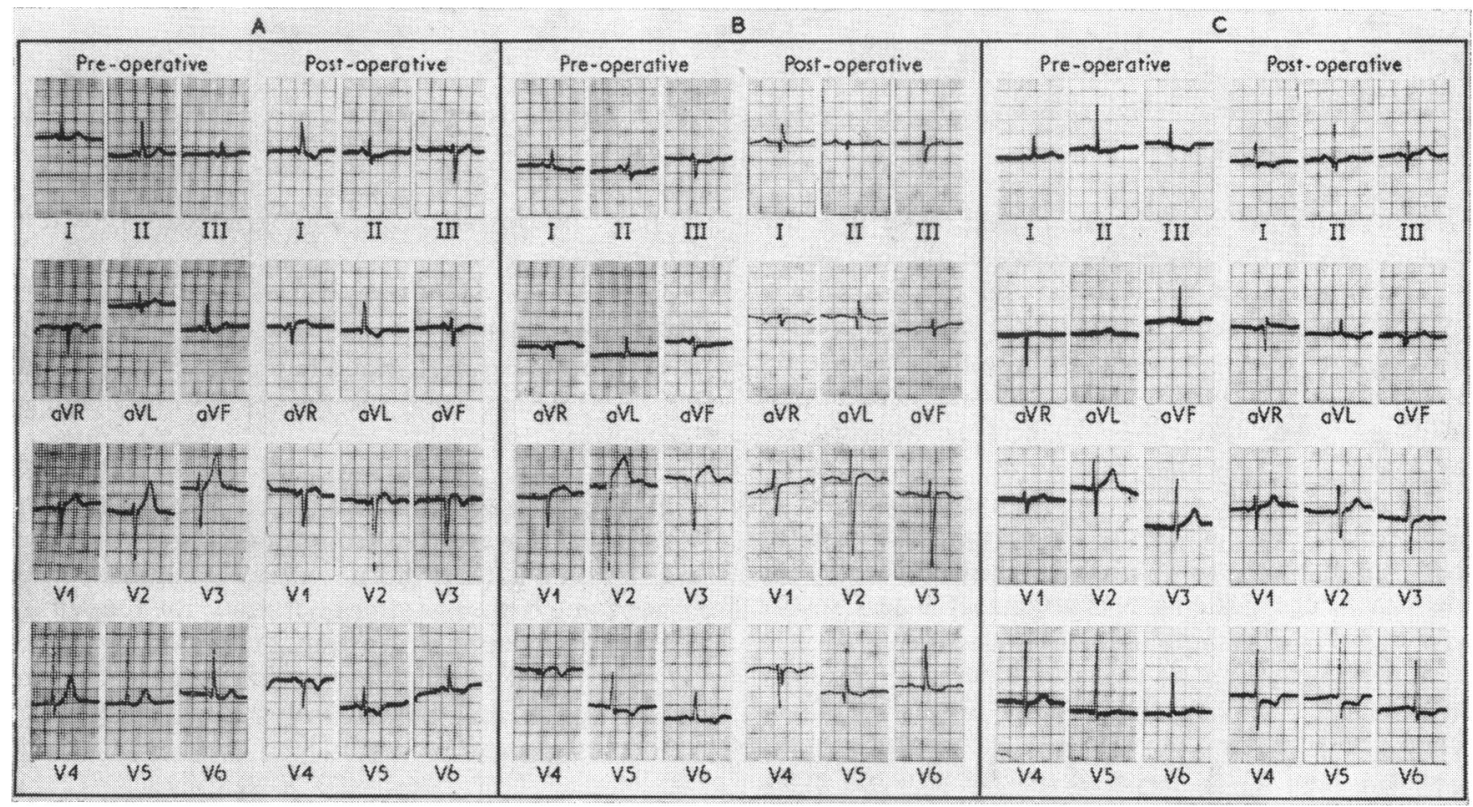

FIG. $2(A, B, C)$ Pre- and postoperative electrocardiograms in 3 angina-free patients. 


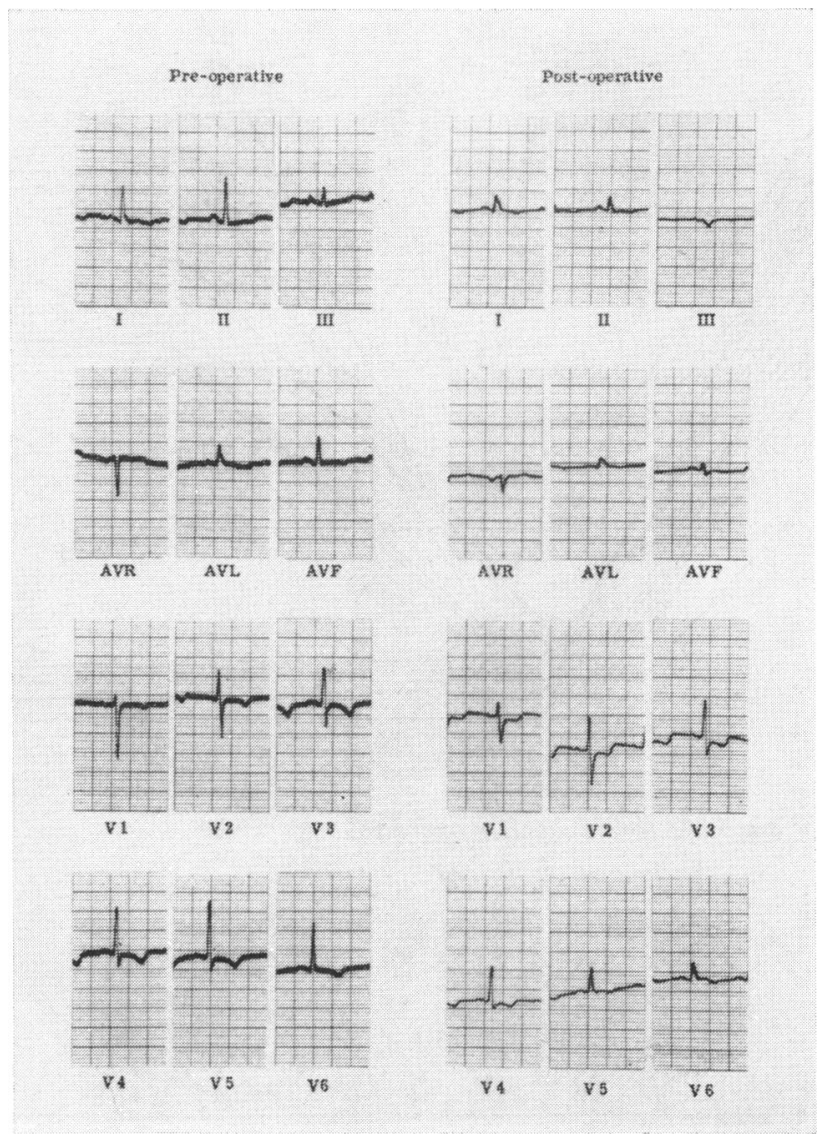

FIG. 3 Electrocardiograms of fourth angina-free patient.

During the late follow-up period, after 4 and 6 months from the respective dates of the restudy, 2 of the angina-free patients started to complain of typical anginal pain (grade $I$ and 2, respectively). One angina-free patient died 7 months after the restudy and the 2 remaining are still free from angina at the present time after 24 and 20 months, repectively, from the date of restudy.

During the late follow-up period angina was of the same grade as before operation, in 5 of the patients in whom this symptom recurred before the restudy. Four patients had angina of a less severe grade and one had angina of more severe grade. In 4 of the angina-free patients postoperative coronary arteriograms showed that a total occlusion of the bypassed artery which received the occluded graft had occurred at the point of insertion of the graft. In the fifth patient a further stenosis was present at the site of the insertion of the graft. Examples of 3 of the pre- and postoperative angiograms are shown in Fig. 4 .

\section{Atrial pacing test}

Atrial pacing was performed before and after operation in Io patients and the results are illustrated in Fig. 5 .

I) Patients free from angina after operation Four patients were free from angina at the time of restudy. One patient did not develop angina during atrial pacing before or after operation; the remaining 3 developed angina at a mean preoperative rate of I $17 / \mathrm{min}$, but after operation 2 were completely pain free at $160 / \mathrm{min}$ and one had only a very slight sensation in the chest at $160 / \mathrm{min}$.

2) Patients with angina after operation Six patients who were complaining of angina at the 

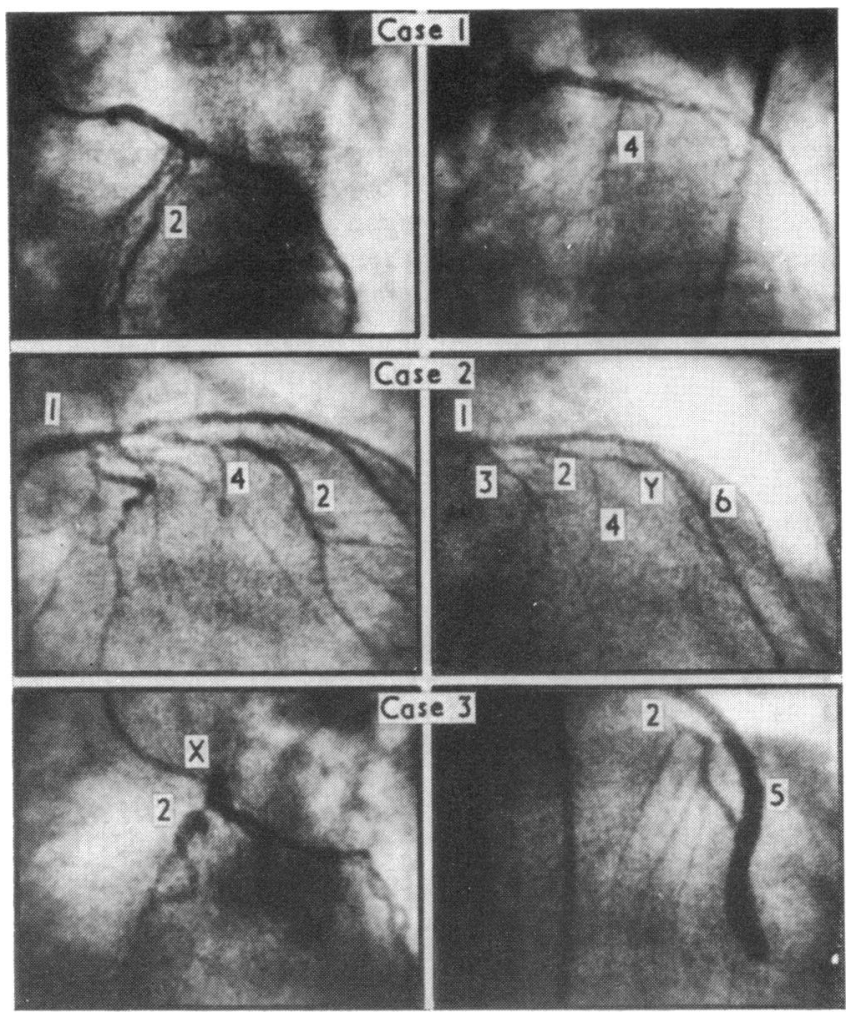

FIG. 4 Pre- and postoperative left coronary angiograms of 3 angina-free patients: I) main trunk of left coronary artery; 2) left anterior descending coronary artery; 3) left circumflex coronary artery; 4) septal branches of the left anterior descending artery; 5) saphenous vein graft; 6) diagonal branch of left coronary artery; X) catheter tip; $Y$ ) point of graft insertion. Case I - Absent anterograde filling of the left anterior descending coronary artery (2) postoperatively; a few septal branches (4) can be seen. Case 2-Total occlusion of the left anterior descending coronary artery at the point of graft insertion. Case 3 - Injection through the graft shows good proximal filling of the left anterior descending coronary artery with filling of septal branches but no filling of the distal segment of the left anterior descending is seen.

time of restudy were paced before and after operation. Two patients were in group $A, 2$ were in group $\mathrm{Br}$, and 2 in group $\mathrm{B} 2$. The mean preoperative pacing rate threshold for the onset of angina was 142 beats $/ \mathrm{min}$. At restudy the mean pacing rate threshold was 148 beats/min. The 2 patients with the left graft patent and the right graft blocked (group B2) could be paced after operation to $160 /$ min compared with preoperative values of $100 / \mathrm{min}$ and $140 / \mathrm{min}$. The remaining 4 patients all had the left graft occluded (and 2 had the right graft occluded as well). All 4 had angina at the same or lower pacing rates after operation (mean preoperative level $152 / \mathrm{min}$; mean postoperative level $\mathrm{I} 42 / \mathrm{min}$ ).

\section{Exercise test}

Fig. 6 shows the pre- and postoperative exercise tolerance in the 14 patients in whom this test was performed. Four patients who were free from angina at the time of restudy are indicated with broken lines.

I) Patients free of angina after operation One of these 4 patients was unable to exercise before surgery, and had an emergency operation. At restudy he was able to perform 5,000 kpm before being stopped by exhaustion. This patient had the left graft patent and the right graft occluded (group B2). In the other patients, free from angina, with the left graft occluded and the right graft patent 
(group $\mathrm{BI}$ ), the postoperative exercise tolerance was found to be slightly improved. Before operation these patients were stopped by angina. At the restudy all 3 were limited by breathlessness and no angina occurred at the maximum work load. These data are shown in the Table which demonstrates that no significant increase in exercise tolerance occurred in patients with postoperative angina or in the 3 pain-free patients of group BI (left graft occluded).

\section{ATRIAL PACING TEST}

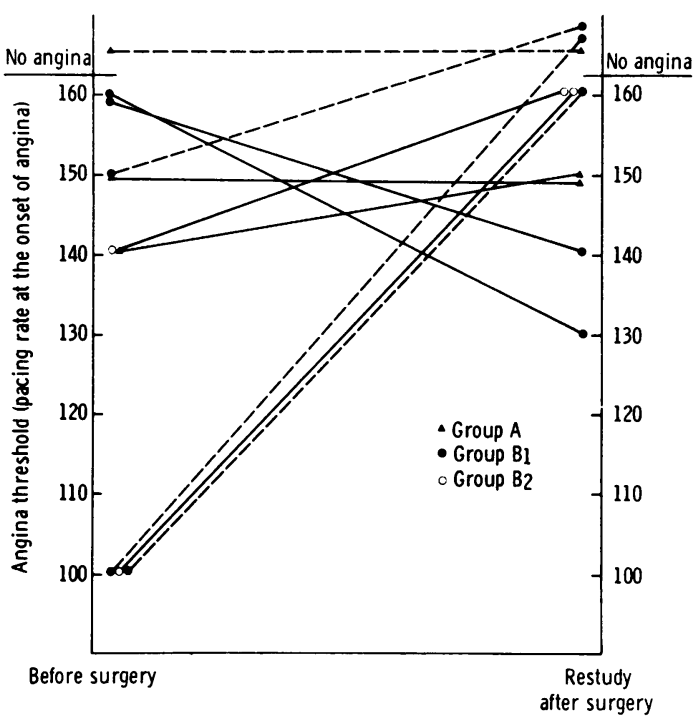

FIG. 5 Atrial pacing before and after operation.
2) Patients with angina after operation Ten patients in whom angina was present at restudy were exercised before and after operation. Two patients had patent left grafts (group B2). One had no increase at all in exercise tolerance after operation and the other increased from $1000 \mathrm{kpm}$ to $1500 \mathrm{kpm}$. There was no significant change in exercise tolerance of 8 patients with occluded left grafts (Table).

\section{Left ventricular end-diastolic pressure}

Recordings of left ventricular end-diastolic pressure were made before and after operation in 12 patients and the results are shown in Fig. 7. In 4 of the 5 angina-free patients (broken lines) the resting left ventricular end-diastolic pressure was normal before operation. At restudy it was found to be practically unchanged in 3 patients and pathologically increased in one (from to to $35 \mathrm{mmHg}$ ). The preoperative left ventricular end-diastolic pressure was normal (less than $10 \mathrm{mmHg}$ ) in 4 and pathologically raised in the other 4 patients with angina (mean value $16.5 \mathrm{mmHg}$ ). At restudy the pressure was normal in 4 and pathologically increased in 4 other patients (mean value $17.5 \mathrm{mmHg}$ ).

If the patients were considered according to the type of occluded graft, group B2 shows a different response from groups $A$ and $B r$. In groups $A$ and Br (left or both grafts occluded), the end-diastolic pressure increased from normal to pathological levels in 4 patients (the mean values rose from 9 to $17.5 \mathrm{mmHg}$ ). In patients of group B2, who were found to have only the right graft occluded and the left graft patent, the left ventricular end-diastolic pressure decreased from abnormal to normal values

TABLE Pre-and postoperative exercise tolerance of 14 patients

\begin{tabular}{|c|c|c|c|c|}
\hline No. of patients & State of grafts & \multicolumn{3}{|c|}{ Total work $(\mathrm{kpm})$ performed before distress } \\
\hline \multicolumn{5}{|c|}{ Free from angina after operation } \\
\hline 3 & $\begin{array}{l}\text { Left blocked, } \\
\text { right patent }\end{array}$ & 1830 & 2300 & +28 \\
\hline $\mathbf{I}$ & $\begin{array}{l}\text { Left patent, } \\
\text { right blocked }\end{array}$ & - & 5000 & 一 \\
\hline \multicolumn{5}{|l|}{4} \\
\hline \multicolumn{5}{|c|}{ Angina after operation } \\
\hline 8 & $\begin{array}{l}\text { Left blocked, } \\
\text { right patent } \\
\text { or blocked }\end{array}$ & 2135 & 2175 & +2 \\
\hline 2 & $\begin{array}{l}\text { Left patent, } \\
\text { right blocked }\end{array}$ & 700 & 950 & - \\
\hline
\end{tabular}


EXERCISE TOLERANCE

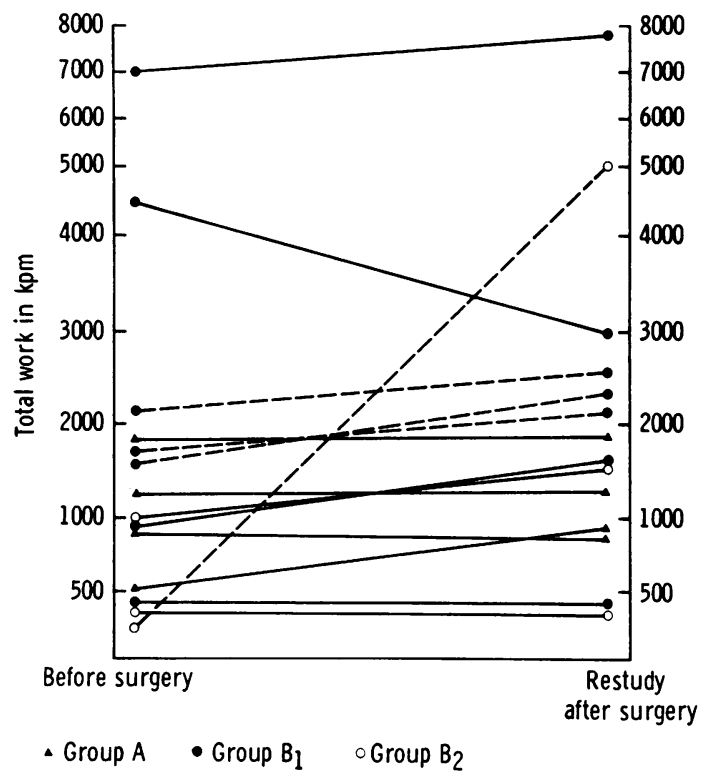

FIG. 6 Exercise tolerance tests before and after operation in 14 patients. in 2 patients. The mean value fell from 26.6 to I2.3 $\mathrm{mmHg}$.

\section{Discussion}

Relief from angina is the most immediate and impressive result so far achieved with coronary artery bypass surgery, and freedom from pain is often regarded as an indirect sign of patent grafts. However, our present findings have shown that the disappearance of angina in previously disabled patients can be associated with occluded venous grafts. Of the I5 patients reported here who were found to have one or both the grafts occluded, 5 were free from angina ( 3 had the left graft occluded and the right graft patent; I had the right graft occluded and the left graft patent; I had both the inserted grafts occluded). The disappearance of angina in patients with one graft patent and one graft occluded could be considered as a partial, but satisfactory, surgical result, since improvement would theoretically imply relief of ischaemia in that area of the myocardium which postoperatively receives blood through the patent graft. However, in 3 patients in the angina-free group with one graft occluded and one graft patent, there was clear electrocardiographic evidence of myocardial infarction in the

\section{L.V.E.D.P.}

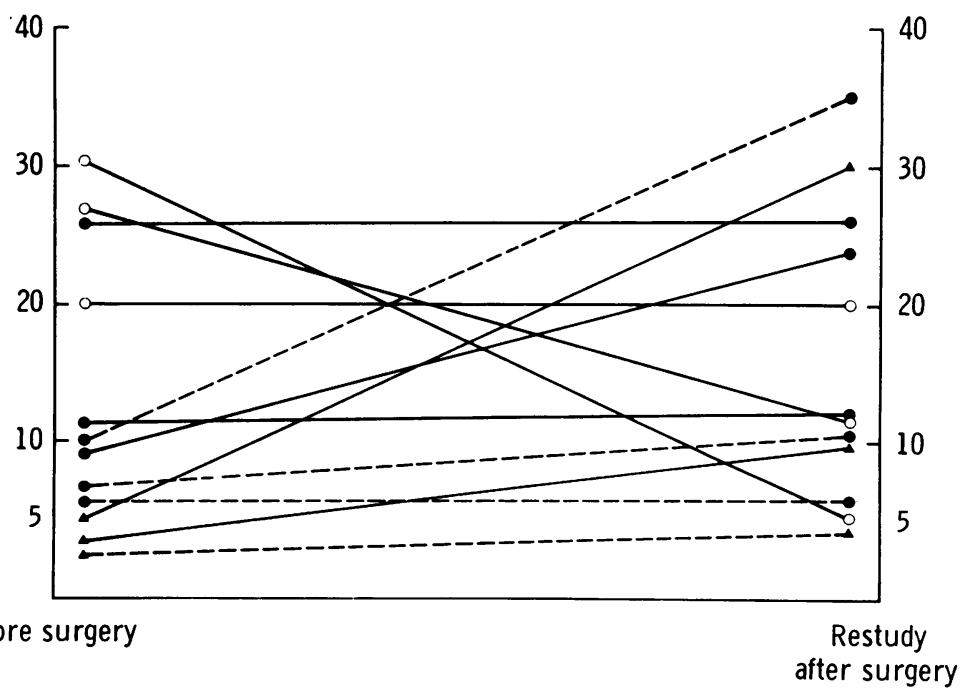

- Group A - Group $B_{1} \quad \circ$ Group $B_{2}$

FIG. 7 Left ventricular end-diastolic pressure in $\mathrm{mmHg}$ before and after operation in 12 patients. 
area of distribution of the previously stenosed coronary artery which received the occluded graft. The postoperative coronary arteriograms give further confirmation of this fact. The bypassed coronary arteries were found to be blocked at the point of insertion of the occluded grafts. It is, therefore, very likely that in these 3 patients necrosis of that ischaemic area of the myocardium previously responsible for the angina accounted for the disappearance of pain. In all of these patients with evidence of infarction the artery involved was the left coronary artery. Occlusion of the grafts to the right coronary artery was not associated with evidence of infarction. It, therefore, seems that particular care should be taken to ensure graft patency when the left coronary artery is involved. Postoperative wound pain and the administration of strong analgesics can mask the usual clinical clues to myocardial infarction, especially if monitoring is restricted to one lead of the electrocardiogram. Daily routine I2-lead electrocardiograms may show up infarction which otherwise may pass unnoticed.

In the 2 other angina-free patients the coronary artery segments distal to the occluded grafts were also blocked. In $I$ of these patients pathological $Q$ waves could not be detected, but clear and persistent electrocardiographic changes occurred after operation indicating anterior subendocardial injury and a sudden change of the direction of the mean QRS vector in the frontal plane. Both of the inserted grafts were occluded. In the other patient, the right graft was occluded but the graft to the left anterior descending coronary artery was patent with good retrograde filling, despite distal occlusion beyond the site of graft insertion (Case 3, Fig. 4). This retrograde filling provided good revascularization in the area of the proximal distribution of the artery, which was clearly ischaemic before operation because of a proximal segmental stenosis. In addition, the extensive pattern of infarction present before operation, with $\mathrm{Q}$ waves in leads II, III, aVF, and VI to V5, may have masked any further small infarction at the time of operation. It has been shown by others that patency of one graft usually leads to significant improvement in the patients' postoperative tolerance (Ross et al., 1972). From the Table it seems that this depends in part on which graft is occluded. If the left graft is occluded, those patients who had angina after operation were limited by angina at the same exercise level as they had been before, even with the right graft patent. On the other hand, in those 3 patients with occluded left grafts who were free from angina after operation, with evidence of myocardial infarction, their exercise tolerance did improve slightly but their end-point was no longer angina but shortness of breath. This change in end-point, from angina to dyspnoea, with very little increase in the amount of exercise performed may suggest graft occlusion with subsequent infarction. However, this point is open to some question in patients who are free from pain, and repeat angiography may be the only way to determine that freedom from pain is caused by successful revascularization and not perhaps by myocardial infarction, unless this is clearly shown by electrocardiography.

From the atrial pacing test it also appears that the postoperative level achieved does depend on which graft is patent. Of patients who were free from pain after operation, those in group BI (left graft occluded and right patent) showed a reduction, and patients in group B2 (left graft patent and right occluded) showed an increase in the pacing rate threshold for the occurrence of angina. It appears from this that patients in group BI were only free from pain after operation because they were not subjecting themselves to exercise stress as great as that which could be simulated by pacing (the converse of the common situation in which patients with angina on minimal exertion do not suffer pain on pacing). In other words, an unsuccessful graft into the left anterior descending is likely to be followed by left ventricular dysfunction which itself limits exercise.

The effect of an occluded saphenous vein graft on left ventricular function again seems to depend on which graft is occluded. In those patients of groups $A$ and BI (left or both occluded) the left ventricular end-diastolic pressure increased from normal to pathological levels in 4 patients and remained unchanged in 5.

Postoperative assessment of patients with occluded vein grafts, both in terms of symptoms and objective measurements, shows distinct differences between those with occlusion of the left graft and those with occlusion of the right. Left graft occlusion is much more likely to be associated with recurrence of symptoms, exercise limitation, and worsening of left ventricular function.

\section{Conclusion}

Freedom from pain does not necessarily indicate success in revascularization and may be associated with myocardial infarction, especially if the occluded graft involves the left coronary artery.

\section{References}

Green, G., Spencer, F. C., Tice, D. A., and Stutzer, S. H. (1970). Arterial and venous micro surgical bypass grafts for coronary artery disease. In XV Annual Meeting of American Association for Thoracic Surgery, Washington D.C., 6-8 April. 
Parsonnet, V., Gilbert, L., Gielchinsky, I., Kortis, H., Zucker, R., Rothfeld, E. L., and Rothfeld, D. (1973). Surgical treatment of coronary artery disease. Fournal of the Medical Society of New Fersey, 70, 185.

Ross, D., Sutton, R., Dow, J., Gonzales-Lavin, L., Hendrix, G., Jefferson, K., MacDonald, L., Petch, M., Smithen, C., and Sowton, E. (1972). Venous graft surgery in treatment of coronary heart disease. British Medical fournal, 2, 644 .
Spencer, F. C., Green, G. E., Tice, D. A., and Glassmann, E. (197I). Bypass grafting for occlusive disease of the coronary arteries - A report of experience with 195 patients. Annals of Surgery, 173, I029.

Requests for reprints to Dr. P. R. Roy, Cardiac Department, Guy's Hospital, London SEI 9RT. 